\title{
ANALISA PROFIT MAKSIMUM USAHATANI LADA KELOMPOK TANI BERKAH MANDIRI DI DESA BATUAH, KECAMATAN LOA JANAN, KABUPATEN KUTAI KARTANEGARA
}

\section{ANAL YSIS OF MAXIMUM PROFIT OF PEPPER FARMERS OF THE BERKAH MANDIRI FARMER GROUP IN BATUAH VILLAGE, LOA JANAN DISTRICT, KUTAI KARTANEGARA REGENCY}

\author{
Aulia Farah Diba*1, Ernita Obeth ${ }^{1}$, Jamaluddin ${ }^{1}$ \\ ${ }^{1}$ Politeknik Pertanian Negeri Samarinda, Kampus Gunung Panjang, Jl. Samratulangi, Samarinda, \\ Indonesia \\ auliafarahd@gmail.com
}

\begin{abstract}
One of the goals of agricultural development is to increase the welfare of farmers, but in fact, there are still many farmers who are not economically prosperous. Increasing the welfare of farmers can be achieved through the success of farming. The achievement of maximum profit is one indicator of the success of the farming business. Batuah Village, which is located in Loa Janan District, is one of the largest producing areas in East Kalimantan. So far, it is not known whether the pepper farming in Batuah Village has reached its maximum profit. This is what encourages researchers to analyze the maximum profit of pepper farming in Batuah Village.

The purpose of this study is to determine how much maximum profit that can be received by farmers based on the total costs that have been incurred. Data obtained through interviews with respondents using a questionnaire. The data obtained were then analyzed using multiple linear regression methods.

The results showed that the maximum profit that the Berkah Mandiri farmer group could get in Batuah Village was Rp. 9,183,253 / ha achieved at a production rate of $560 \mathrm{~kg} / \mathrm{ha}$. So far, farmers have not reached the maximum production and maximum profit because the average farmer's production is $517 \mathrm{~kg} / \mathrm{h}$ a and the average farmer's profit is Rp. 7,548,229 / ha. Therefore, to achieve maximum profit, pepper farmers in the Berkah Mandiri farmer groups need to increase their productivity.
\end{abstract}

Keywords: Pepper, Profit

\section{PENDAHULUAN}

Indonesia adalah negara agraris yang memiliki sumber daya alam yang melimpah dari Sabang sampai Merauke. Indonesia berada pada daerah yang tropis dan memiliki curah hujan yang tinggi, oleh karena itu tanahnya menjadi subur dan berbagai jenis tumbuhan bisa tumbuh dengan cepat, maka dari itu Indonesia memiliki kekayaan yang banyak dikarenakan alasan tadi. Separuh penduduk Indonesia bermata pencaharian sebagai petani.

Pembangunan pertanian memiliki tujuan untuk mewujudkan kesejahteraan masyarakat terutama petani. Kesejahteraan petani selalu menjadi tujuan utama pada tahapan kegiatan pembangunan pertanian. Pada tahun 2010-2014, salah satu Rencana Strategis Kementrian Pertanian adalah meningkatkan kesejahteraan para petani (Kementan, 2010 dalam Ramadhani 2015). Petani memiliki peran penting bagi pemerintah dalam rangka mewujudkan visi pembangunan pertanian, yaitu "Terwujudnya sistem pertanian industri berdaya saing, berkeadilan, dan berkelanjutan guna menjamin ketahanan pangan dan kesejahteraan masyarakat pertanian" (Bappenas, 2006 dalam Pradipta 2017). Karena petani memiliki peran yang penting, maka seharusnya nilai tawar mereka harus tinggi dan kesejahteraan mereka harus mendapat perhatian lebih. Pada kenyataannya, 
masih banyak petani yang belum sejahtera. Masih banyak petani yang tidak sejahtera secara ekonomi. Salah satu hal yang dapat dilakukan oleh petani untuk meningkatkan kesejahteraannya adalah dengan meningkatkan profit yang diperoleh dari usaha taninya.

Ada beberapa faktor yang mempengaruhi tinggi rendahnya produksi pertanian seperti luas lahan, sarana produksi, modal dan tenaga kerja. Penggunaan sarana produksi ini menimbulkan biaya produksi (Mubyarto, 1994). Petani dapat meningkatkan profit dari usaha taninya ketika penerimaan yang diperoleh lebih besar dari total biaya produksi yang dikeluarkan (Syafitri, 2012).

Lada merupakan komoditi yang telah lama dikembangkan oleh rakyat di Kalimantan Timur. Pada tahun 2019, luas areal lada rakyat di Kalimantan Timur tercatat seluas 8.921 ha dengan jumlah produksi sebanyak 5.799 ton lada kering (DisBun, 2020). Hasil atau produksi dari tanaman lada tersebut semuanya dipasarkan guna memenuhi kebutuhan konsumsi dalam negeri dan luar negeri.

Salah satu daerah penghasil lada terbesar di Kalimantan Timur adalah di Kabupaten Kutai Kartanegara, di Desa Batuah, Kecamatan Loa Janan. Ada beberapa desa yang mengembangkan tanaman lada yakni Dusun Surya Bakti $\mathrm{Km} 28$ dan Dusun Tani Bahagia Km 31 Kecamatan Loa Janan Kabupaten Kutai Kartanegara dengan luas lahan sekitar $19.837,8$ ha sedangkan luas lahan pertaniannya sekitar 5.979,2 ha (DisBun, 2018). Berdasarkan hasil survey awal diketahui bahwa petani lada mengeluhkan tentang turunnya produksi lada. Hal ini tentu berdampak kepada besarnya penerimaan yang mereka peroleh dari usaha tani lada mereka. Namun belum diketahui apakah pendapatan yang selama ini diterima oleh petani lada sudah maksimum atau belum. Oleh karena itu, peneliti tertarik untuk meneliti atau menganalisa profit dari usaha tani lada di Desa Batuah.

Berdasarkan uraian sebelumnya, maka dapat disusun permasalahan penelitian, yaitu: Berapa besarnya produksi yang memberikan profit maksimum dan berapa besarnya profit maksimum. Agar penelitian ini lebih terfokus maka penelitian ini dibatasi pada permasalahan yang berkaitan dengan pendapatan usaha tani lada Kelompok Tani Berkah Mandiri di Desa Batuah, Kecamatan Loa Janan, Kabupaten Kutai Kartanegara.

Penelitian ini bertujuan untuk mengetahui berapa besarnya produksi yang memberikan profit maksimum dan untuk mengetahui berapa besarnya profit maksimum petani. Hasil yang diharapkan dalam penelitian ini adalah agar memberikan masukan kepada kelompok tani Berkah Mandiri agar mengetahui berapa banyak produksi yang harus di produksi untuk mencapai profit maksimum.

\section{METODOLOGI}

\section{Metode Pengambilan Data}

a. Wawancara

Wawancara merupakan

pengumpulan data dengan melakukan wawancara langsung dengan para petani. Dalam teknik wawancara peneliti menggunakan wawancara berstruktur dimana peneliti mempersiapkan daftar pertanyaan sebelum melakukan wawancara

\section{b. Kuesioner}

Kuesioner yaitu membuat daftar pertanyaan yang digunakan untuk mempermudah dalam mengumpulkan data yang diperlukan dan diajukan kepada responden. Pertanyaan yang ditujukan kepada petani adalah mengenai identitas responden, keadaan pertanian responden, produksi dan pemasaran, dan biaya produksi.

\section{Analisa Data}

\section{a. Uji Regresi}

Regresi dapat digunakan untuk memprediksi produksi di masa yang akan datang berdasarkan data masa lalu (Siregar, 2013: 301). Peneliti menggunakan regresi untuk memperoleh 
prediksi total biaya (TC) berdasarkan data produksi $(\mathrm{Q})$ yang dinyatakan dalam bentuk persamaan (fungsi biaya).

Penelitian ini menggunakan 2 faktor yaitu total biaya (TC) dan produksi (Q). Namun secara statistika menggunakan 3 variabel yaitu TC, $Q$, dan $\mathrm{Q}^{2}$. Dengan demikian, persamaannya adalah :

$$
T C=a+b_{1} Q+b_{2} Q^{2}
$$

Dimana :

$$
\begin{array}{ll}
\mathrm{TC} & =\text { Total Cost atau Total Biaya } \\
\mathrm{a} & =\text { Bilangan konstanta } \\
\mathrm{b}_{1} & =\text { standar koefisien pertama } \\
\mathrm{b}_{2} & =\text { standar koefisien kedua }
\end{array}
$$

b. Analisa Profit Maksimum

Menurut Basuki dan Prawoto (2014) profit maksimum dapat diketahui ketika

Dimana :

$$
\mathrm{P}=\mathrm{MC}
$$

P: Harga produk

MC: Biaya marginal

Selanjutnya, nilai MC diperoleh melalui rumus $\mathrm{MC}=\frac{\Delta T C}{\Delta Q}$.

\section{c. Analisa Profit Usaha Tani Menurut Soekartawi (1995), rumus yang digunakan dalam} menghitung profit dan penerimaan usaha tani yakni sebagai berikut :

$$
\begin{aligned}
& \Pi=T R-T C \\
& T R=P \times Q
\end{aligned}
$$

Dimana :

$$
\begin{array}{ll}
\text { T } & \text { : Profit }(\mathrm{Rp}) \\
\text { TR } & : \text { Total penerimaan }(\mathrm{Rp}) \\
\text { TC } & : \text { Total biaya }(\mathrm{Rp}) \\
\mathrm{P} & : \text { Harga produk }(\mathrm{Rp} / \mathrm{Kg}) \\
\mathrm{Q} & : \text { Jumlah produksi }(\mathrm{Kg})
\end{array}
$$

\section{HASIL DAN PEMBAHASAN}

\section{Hasil}

\section{a. Profit Usaha Tani}

Biaya produksi, jumlah produksi, harga jual lada, besarnya penerimaan dan besarnya profit dari seluruh responden dapat dilihat dalam Tabel 1. Tabel 1.
Tabel 1 menunjukkan bahwa petani lada dalam kelompok tani Berkah Mandiri mengeluarkan biaya total sebesar $\mathrm{Rp}$. 12.629.867 per hektar untuk menghasilkan lada sebanyak $517 \mathrm{~kg}$. Dengan harga jual Rp. 38.952 petani mendapatkan profit sebesar Rp. 7.548.229 per hektar.

b. Analisa Profit Maksimum Langkah pertama adalah dengan melakukan analisa regresi linier berganda untuk memperoleh persamaan fungsi biaya total (TC). Dari regresi linier berganda diperoleh persamaan TC adalah:

$\mathrm{TC}=81.571 .631-283.762 \mathrm{Q}+288 \mathrm{Q}^{2}$

Langkah kedua adalah mencari produksi (Q) yang memberikan keuntungan maksimum, maka persamaan TC diturunkan terhadap $Q$ : $\mathrm{MC}=\frac{d T C}{d Q}=\frac{81.571 .631-283.762 \mathrm{Q}+288 \mathrm{Q} 2}{Q}$ $=-283.762+576 Q$

Agar profit maksimum, maka :

$\mathrm{P}=\mathrm{MC}$

$38.952=-283.762+576 Q$

$-576 Q=-283.762-38.952$

$-576 Q=-322.714$

$\mathrm{Q}=560 \mathrm{~kg}$

Langkah ketiga adalah menghitung profit maksimum yang dixterima oleh petani dengan rumus:

$$
\begin{aligned}
\mathrm{TR} & =\mathrm{P} \times \mathrm{Q} \\
& =\mathrm{Rp} .38 .952 \times 560 \mathrm{~kg} \\
& =\mathrm{Rp} .21 .813 .120 \\
\Pi & =\mathrm{TR}-\mathrm{T} \mathrm{C} \\
& =\text { Rp. } 21.813 .120-\text { Rp. } 12.629 .867 \\
& =\text { Rp. } 9.183 .253
\end{aligned}
$$

Dengan total biaya sebesar $\mathrm{Rp}$. 12.629.867 maka profit maksimum yang dapat diperoleh petani adalah sebesar Rp. 9.183.253. 
Tabel 1. Total Cost (TC)/Ha dan Hasil Produksi (Q)/Ha Lada di Desa Batuah, Kecamatan Loa Janan, Kabupaten Kutai Kartanegara di Tahun 2019

\begin{tabular}{ccccccc}
\hline Responden & $\begin{array}{c}\text { Harga jual/Kg } \\
(\mathrm{Rp})\end{array}$ & $\begin{array}{c}\text { Profit /Ha } \\
(\pi)\end{array}$ & $\begin{array}{c}\text { Penerimaan/ } \\
\text { Ha (TR) }\end{array}$ & $\begin{array}{c}\text { Total cost } \\
\text { /Ha (TC) }\end{array}$ & $\begin{array}{c}\text { Produksi/Ha } \\
(\mathrm{Q})\end{array}$ & $\mathrm{Q}^{2}$ \\
\hline 1 & 38.000 & 8.870 .000 & 21.280 .000 & 12.410 .000 & 560 & 313.600 \\
2 & 40.000 & 7.990 .000 & 22.400 .000 & 14.410 .000 & 560 & 313.600 \\
3 & 40.000 & 7.800 .000 & 22.800 .000 & 15.000 .000 & 570 & 324.900 \\
4 & 35.000 & 1.650 .000 & 14.700 .000 & 13.050 .000 & 420 & 176.400 \\
5 & 40.000 & 10.370 .000 & 21.200 .000 & 10.830 .000 & 530 & 280.900 \\
6 & 40.000 & 10.415 .000 & 21.600 .000 & 11.185 .000 & 540 & 291.600 \\
7 & 40.000 & 9.323 .600 & 24.400 .000 & 15.076 .400 & 610 & 372.100 \\
8 & 40.000 & 8.525 .000 & 24.000 .000 & 15.475 .000 & 600 & 360.000 \\
9 & 38.000 & 8.328 .200 & 20.900 .000 & 12.571 .800 & 550 & 302.500 \\
10 & 38.000 & 6.708 .000 & 19.000 .000 & 12.292 .000 & 500 & 250.000 \\
11 & 40.000 & 7.568 .000 & 20.400 .000 & 12.832 .000 & 510 & 260.100 \\
12 & 40.000 & 7.920 .000 & 20.000 .000 & 12.080 .000 & 500 & 250.000 \\
13 & 40.000 & 9.312 .000 & 19.600 .000 & 10.288 .000 & 490 & 240.100 \\
14 & 38.000 & 4.250 .000 & 17.860 .000 & 13.610 .000 & 470 & 220.900 \\
15 & 40.000 & 5.920 .000 & 20.000 .000 & 14.080 .000 & 500 & 250.000 \\
16 & 40.000 & 7.852 .000 & 20.400 .000 & 12.548 .000 & 510 & 260.100 \\
17 & 40.000 & 9.465 .000 & 19.600 .000 & 10.135 .000 & 490 & 240.100 \\
18 & 40.000 & 9.370 .000 & 20.000 .000 & 10.630 .000 & 500 & 250.000 \\
19 & 38.000 & 2.640 .000 & 15.960 .000 & 13.320 .000 & 420 & 176.400 \\
20 & 38.000 & 7.826 .000 & 20.140 .000 & 12.314 .000 & 530 & 280.900 \\
21 & 35.000 & 6.410 .000 & 17.500 .000 & 11.090 .000 & 500 & 250.000 \\
\hline Rata-rata & 38.952 & 7.548 .229 & 20.178 .095 & 12.629 .867 & 517 & 269.724 \\
\hline
\end{tabular}

\section{Pembahasan}

Profit Usaha Tani

Dari hasil analisa diketahui bahwa dengan total biaya sebesar $\mathrm{Rp}$. 12.629.867 maka petani dapat menghasilkan lada $560 \mathrm{~kg} / \mathrm{ha}$ agar diperoleh profit maksimum sebesar Rp. 9.183.253/ha nya. Namun pada kenyataannya petani hanya memproduksi $517 \mathrm{~kg} / \mathrm{ha}$ dan hanya memperoleh ratarata profit sebesar Rp. 7.548.229/ha. Bila dibandingkan dengan negara lain, produktivitas tanaman lada Indonesia masih rendah $(<1000 \mathrm{~kg} / \mathrm{ha})$. Vietnam produktivitasnya sudah mencapai 2.220 $\mathrm{kg} / \mathrm{ha}$ (Tuan Nam, 2008). Masyarakat yang menjalankan usaha tani di Desa Batuah, Kecamatan Loajanan, Kabupaten Kutai Kartanegara memiliki perkebunan lada sendiri (Hak Milik).
Petani banyak mengeluhkan harga lada yang murah yang disebabkan oleh turunnya harga lada di pasar. Harga buah lada pada tahun 2019 mengalami penurunan dari yang biasanya Rp.100.000-Rp.150.000/Kg kini hanya Rp.35.000/Kg. Selain itu, petani mengeluhkan penurunan produksi akibat tanaman yang mati Menurut para petani, hal ini disebabkan oleh tanah yang sudah tidak subur akibat adanya penambangan di sekitaran lahan mereka. Hal ini didukung oleh Listiyani (2017) yang mengatakan bahwa salah satu dampak pertambangan terhadap lingkungan adalah penurunan produktivitas lahan, meningkatnya kepadatan tanah, terjadinya erosi dan sedimentasi, terjadinya gerakan tanah atau longsoran dan perubahan iklim mikro. Faktor lain yang menyebabkan 
turunnya produksi adalah penyakit yang menyerang tanaman. Petani biasanya panen 2 kali dalam setahun namun sejak tahun 2019 ini hanya panen sekali. Hal ini didukung oleh Daras dan Pranowo (2009) yang menyatakan bahwa produktivitas lada nasional terus menurun dalam sepuluh tahun terakhir. Faktor yang mempengaruhi produksi lada ialah gangguan penyakit, antara lain penyakit busuk pangkal batang yang disebabkan oleh Phytophthora capsici dan penyakit kuning yang disebabkan oleh nematode (Manohara et al. 2006).

\section{KESIMPULAN}

1. Jumlah produksi yang dapat memberikan keuntungan maksimum bagi petani lada di kelompok tani Berkah Mandiri adalah $560 \mathrm{~kg} / \mathrm{ha}$.

2. Dengan total biaya sebesar Rp.12.629.867 maka profit maksimum petani pada kelompok tani Berkah Mandiri adalah Rp. 9.183.253/ha nya.

\section{DAFTAR PUSTAKA}

Arikunto S. 2010. Prosedur Penelitian Suatu Pendekatan Praktik. Jakarta: Rineka Cipta.

Basuki A,T dan Prawoto N. 2014. Teori Pengantar Ekonomi. Logo Penerbit, Yogyakarta. Hal:175.

Daras U, Pranowo D. 2009. Kondisi kritis lada putih Bangka Belitung dan alternatif pemulihannya. J Litbang Pert. 28(1):1-6.

Dinas Perkebunan Kutai Kartanegara 2018. Kejayaan Lada Kukar, Bisakah Kita Kembalikan. Kutai Kartanegara.

Dinas Perkebunan. 2020. Lada. Kalimantan Timur.

Hadisapoetra, S. 1973. Biaya dan Pendapatan dalam Usahatani. BPFE UGM. Yogyakarta.

Husni, A., K. Hidayah, Maskan. 2014. Analisis finansial usahatani cabai rawit (Capsicum frutescens) di Desa Purwajaya Kecamatan Loa Janan. Jurnal ARIROF. 13 (1) : 49-52.
Kuswandi. 2005. Meningkatkan Laba Melalui Pendekatan Akuntansi Keuangan dan Akuntansi Biaya. PT. Elex Media Komputindo, Jakarta.

Listiyani N. 2017. "Dampak Pertambangan Terhadap Lingkungan Hidup Di Kalimantan Selatan Dan Implikasinya Bagi Hak-Hak Warga Negara". Vol. 9, No. 1:67.

Manohara D, Wahid P, Wahyono D, Nuryani Y, Mustika I, Laba IW, Yuhono, Rivai AM, Saefudin. 2006. Status Teknologi Tanaman Lada. Di dalam: Prosiding Status Teknologi Tanaman Rempah dan Aneka Tanaman Industri: 200626 Sep; Parangkuda-Sukabumi (ID): Pusat Penelitian Tanaman Perkebunan, Deptan. Hal 1-54.

Mubyarto. 1994. Pengantar Ekonomi Pertanian. LP3ES, Jakarta.

Mulyadi. 2001. Sistem akuntansi. Edisi ketiga. Jakarta: Salemba Empat

Prasetya, Priya. 1995. IImu Usahatani II. UNS Press. Surakarta.

Ramdhani H., Soni A.N., Muhammad F. $2015 . \quad$ "Peningkatan Kesejahteraan Petani dengan Penguatan Kelompok Tani". Prosiding KS: Riset \& PKM. Vol.2, No.3:301-444.

Siregar, Sofyan. 2013. Metode Penelitian Kuantitatif. Jakarta: Fajar Interpratama Mandiri.

Soekartawi. 1995. Analisis Usahatani. Universitas Indonesia Press. Jakarta.

Sutrisno. 2019. "Analisis Breakvenpoin Budidaya Kangkung Dalam Meningkatkan Pendapatan Masyarakat Di Desa Kedungmakam Kecamatan Jatirogo Tuban" [Skripsi]. Bojonegoro. Universitas Bojonegoro.

Syafitri R. 2012. "Analisis Pendapatan dan Efisiensi Alokatif Usahatani Lada (Piper nigrum L.) di Desa Batuah Kecamatan Loa Janan Kabupaten Kutai Kartanegara". EPP. Vol.9, No.1:35-41. 
Jurnal Agriment 5(1):1-6, 2020

Tuan Nam T.N. 2008. Report : Market

Management of Natural Resouce and Quality Assesment of Peper in Central Vietnam. $35 \mathrm{p}$. 